\title{
哈萨克斯坦 PKOP 炼厂重催装置再生器祄里施工技术
}

\author{
张勇张东王荣青吴俊常红雷
}

中国石油天然气第七建设有限公司，山东 青岛 266300

[摘要] 哈萨克斯坦 PKOP 奇姆肯特炼油厂，是哈国三大炼油企业之一，位于古丝绸之路交汇点的南哈州首府奇姆肯特市。 在 PK 炼油厂中, 重油催化裂化装置是核心装置, 随着时代的进步, 装置运行长周期化、原材料重质化及催化剂的硬质化等因 素使得装置运行工况越来越苛刻, 反应再生系统设备祄里质量是保证装置能否长、满、优运行的先决条件。衬里施工是一个 特殊作业过程, 因此对祄里施工的全过程严密监控有重要意义，文章中运用衬里施工全过程严密监控法，从工程难点、施工 准备、施工过程监督技术、质量保证措施等几个方面，阐述 PK 炼厂中再生器保证祄里质量的可行性施工技术，祄里施工完成 后，效果良好，对海外其他项目中大型设备祄里有借鉴意义。

[关键词]一带一路; 催化装置; 祄里; 全过程严密监控法

DOI：10.33142/aem.v1i2.897 中图分类号: F426.22

文献标识码：A

\section{Construction Technology of Regenerator Lining for Re-urging Device of PKOP Refinery in Kazakhstan}

\author{
ZHANG Yong, ZHANG Dong, WANG Rongqing, WU Jun, CHANG Honglei \\ The seventh construction company of China national petroleum, qingdao, Shandong, 266300, China
}

\begin{abstract}
Kazakhstan's PKOP Chimkent Refinery is one of Kazakhstan's three major oil refineries. It is located in Chimkent, the capital city of South Kazakhstan at the junction of the ancient Silk Road.

In PK refinery, heavy oil catalytic cracking unit is the core unit. With the progress of the times, the operating conditions of the unit are more and more rigorous due to factors such as periodicity of unit operation, heavy raw materials and hardening of catalyst. The quality of equipment lining in reaction regeneration system is the precondition to ensure the long, full and good operation of the unit. Conditions, and lining construction is a special operation process, so it is of great significance to closely monitor the whole process of lining construction. This paper describes the lining of regenerator in PK refinery from several aspects, such as engineering difficulties, construction preparation, construction process supervision technology and quality assurance measures, using the method of strict control in the whole process of lining construction. How to ensure the feasibility of lining quality construction technology, lining construction after completion, good results, other projects abroad in large equipment lining reference.
\end{abstract}

Keywords: The Belt and Road; catalytic device; lining, whole process tight monitoring method

\section{1 工程概况}

PKOP 奇姆肯特炼油厂重油催化裂化装置再生器采用了 “冷壁” 设计, 涉及祄里料有 A 级、C2、C3 型号, 祄里施工 总量为 $153 \mathrm{~m}^{3} ，$ 除部分再生器内件在国内祄里并烘干后发运，其余均为在哈萨克现场施工。

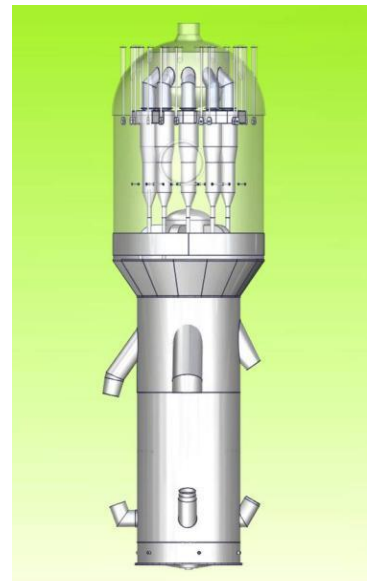

图 1 再生器外形图 
表 1 反应再生系统设备祄里工程量

\begin{tabular}{ccccc}
\hline 序号 & 设备名称 & 衬里型号 & 单位 & 方量 $\left(\mathrm{m}^{3}\right)$ \\
\hline 1 & 再生器内件 & A 级 & 立方米 & 12.54 \\
2 & 再生器壳体 & $\mathrm{C} 2$ & 立方米 & 38.3 \\
3 & 再生器壳体 & $\mathrm{C} 3$ & 立方米 & 102.8 \\
\hline
\end{tabular}

\section{2 工程难点、特点}

(1) 哈萨克斯坦工业化正处于进程中, 目前还不具备生产祄里材料的能力, 所有的锚固件、焊材、不定性耐火材 料需要从中国发运至施工现场。

（2）装置设备及祄里材料跨国运输周期长，祄里材料从生产、发运至现场大约需要 $2 \sim 3$ 个月时间，祄里材料的 发运时间应结合设备的发运时间确定。

（3）本工程祄里材料为水硬性结合祄里，结合剂为高铝水泥，属于有时效性的材料，水泥的有效保管期一般为三 个月, 水泥容易吸湿结块, 一旦水泥结块不能使用, 将严重影响施工进度。

（4）哈萨克斯坦的气候属于典型的干旱大陆性气候， 1 月平均气温 $-19^{\circ} \mathrm{C}$ 至 $-4^{\circ} \mathrm{C}, 7$ 月平均气温 $19^{\circ} \mathrm{C}$ 至 $26^{\circ} \mathrm{C}, 8$ 月份炎热干燥, 最高气温超过 $40^{\circ} \mathrm{C}$, 夏季炎热干燥, 冬季寒冷, 10 月份步入雨季, 11 月份开始降雪, 整个装置的祄里 施工跨越一年四季，需要多种防护措施。

（5）本工程祄里作业不仅要符合中、哈两国施工规范及验收标准的要求，还要执行 UOP 文件。

\section{3 施工准备}

\section{1 人员的准备}

(1) 根据工程量和施工总体进度目标确定人员需求量, 本工程 2017 年祄里相关人员高峰期达 53 人, 2018 年施工 再生器壳体时，人数达 80 人，至少提前六个月办理相关人员护照、签证等出国手续。

（2）人员进入现场后，应对祄里的各工种进行培训，包括施工规范、安全规范的解说，让施工人员作业规范化; 再对本工程的施工方案交底; 在不同厂家材料、不同祄里结构开工前, 现场再次针对材料性能及作业重点交底; 施工 过程中针对个别工种施工纠偏交底，更好的指导和规范工人施工。

\section{2 机具的准备}

根据工程量和施工部署确定机具的种类和数量，并且至少在开工前三个月办理发运手续。

（1）由于国外工业化程度不同，从中国入场的工器具损坏后在当地很难配置零件，维修困难，在选用机具、工具 时应考虑放大备用系数, 对于消耗大、磨损严重的零部件也应备用。

（2）机具等应在中国发运前进行各项检查，确保设备完好；机具入场后应再次复查，并做好维护记录。

\section{3 材料的准备}

祄里材料由国内发出至到达哈萨克 PK 炼厂现场大约需要两个月, 周期特别长, 且祄里料中的结合剂为高铝水泥, 其一般储存期为三个月，故祄里材料应结合设备的发运计划分批次发运，且应先发针固件后发不定形耐火材料。哈萨 克缺少有资质的检验试验单位，祄里材料应在发运前完成原材料的验收工作。不定形耐火材料应有采购单位进行检验 试验，检验试验应在有资质的实验室进行，发运时应将质量证明文件及复验报告等资料一起发往现场。

为解决祄里结合剂的运输周期长与结合剂的储存期短的矛盾, 我们和祄里材料生产厂家多次沟通分析, 原材失强 主要表现为水泥受潮、结块, 改良水泥的储存方式, 加强密封措施可以延长储存期。在订货技术协议中明确结合剂采 用三层密封, 从外到内分别为: 铁桶加密封圈密封、大塑料袋密封、水泥单包密封, 每 4 桶水泥用一个托盘固定。发 运前测试, 将桶落入水中, 水泥不受影响。用此方式密封的水泥在六个月内均没有发生受潮结块现象, 复验性能符合 要求, 此包装方式可以将水泥的储藏期提高至六个月。而国内运输传统的包装方式, 当材料经过 2 个月的运输到达现 场时已经因结块而失强。

通过这两次发运情况来看, 发运至国外的祄里料, 传统的包装方式无法满足要求, 给工程顺利开展造成影响, 结 
建筑工程与管理・2019 第1卷 第2期

合剂与集料应分开包装，结合剂采用 3 层防潮包装能够有效防潮。此包装方式可在国外工程水硬性结合剂的运输方式 中推广。

\section{4 施工过程监控技术}

祄里作为一个特殊工序, 每个环节都可能对祄里的最终质量产生影响, 所以应严格按照技术要求监控每一个施工 环节。虽然不同祄里结构的施工各有要求，但主要施工环节大同小异，其主控环节为：祄里原材料验收、锚固件焊接、 基层处理、祄里拌制、祄里（浇筑）捣打、祄里养护、工程试样的留置、祄里烘干、成品保护。

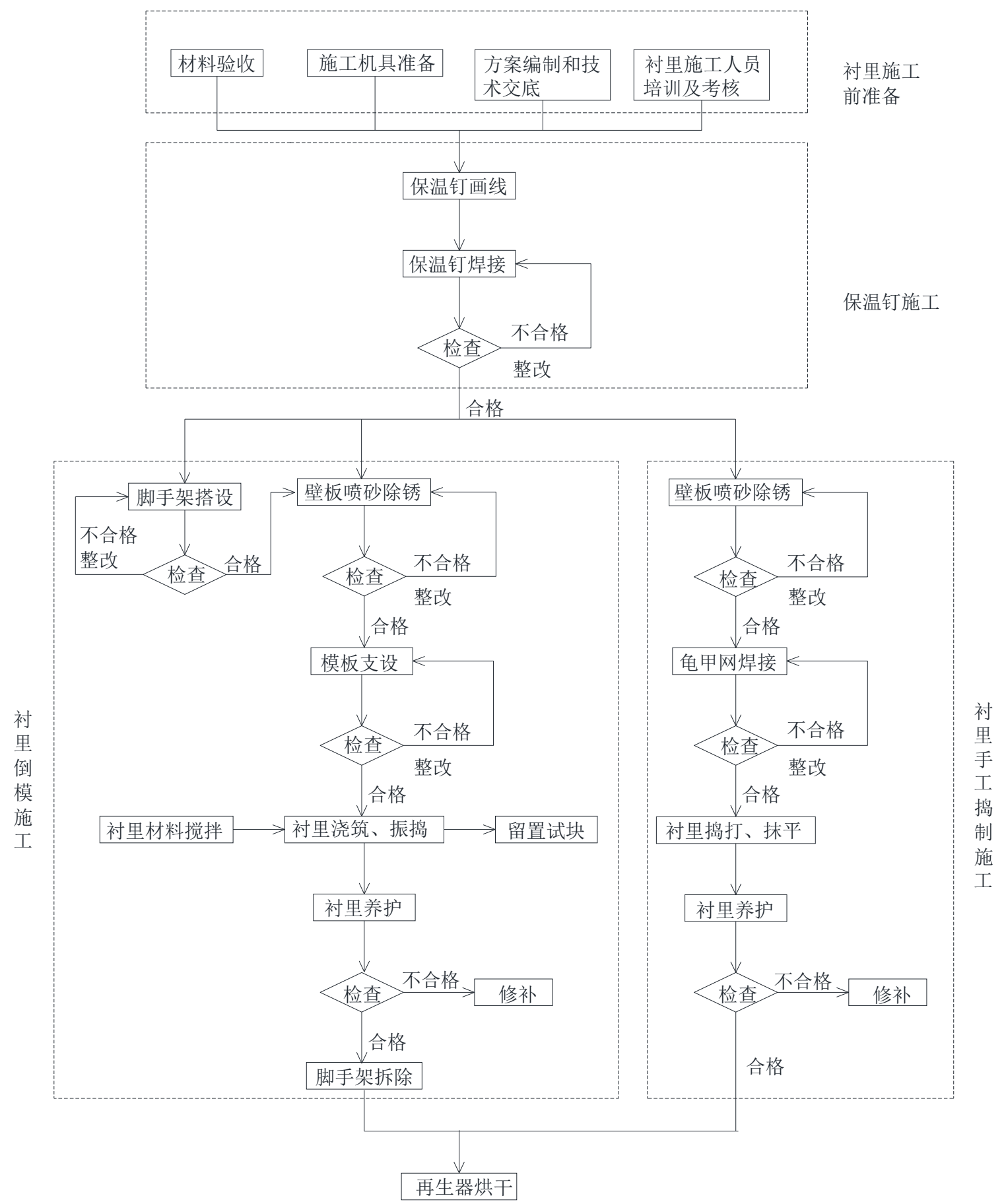

图 2 再生器祄里施工工艺流程图 


\section{1 再生器衬里型式}

再生器是催化裂化装置核心设备, 内部具有高温、冲刷、磨损、腐蚀等工艺特点, 国内目前一般采用带龟甲网的 隔热耐磨双层祄里型式, 祄里结构复杂、施工工序多、施工周期长、造价高, 而 PK 炼厂现代化改造项目中再生器壳体 采用了钢纤维隔热耐磨单层祄里, 针固件为 $S A(\Omega$ 型) 针固钉, 材质为 304 , 钢纤维为 $S 30408$ 弓形 $(\phi 0.4 \mathrm{~mm} \times 25 \mathrm{~mm})$, 这种结构施工灵活, 节约材料, 由于钢纤维的增强作用, 提高了祄里材料的整体强度, 增加了耐冲刷性, 提高了衬里 的抗热震能力。

\section{1.1 针固件的设置}

针固件在安装前, 应在设备内壁根据针固件的布置图划线, 确定针固件的排列位置; 设备过渡段、封头等异形部 位针固钉应适当加密; 针固钉布置时应避开焊道, 焊道两侧 $75 \mathrm{~mm}$ 作为针固钉布置起点。

$\Omega$ 型针固钉的点焊布置, 应按照划线的交点作为针固件的定位点, 针固钉的开口方向应符合图纸及 UOP 文件的要 求。

针固钉的焊接应用手工电弧焊, 采用 A307 焊材, 焊接的形式国内炼厂通常按照 GB50474《隔热耐磨祄里技术规范》 第 5.3.3 条 “ $\Omega$ 型锚固钉应在直段两侧焊接, 每侧焊缝长度不应小于 $25 \mathrm{~mm}$ ” 的要求; 本工程壳体采用 $\mathrm{C} 2$ 级、C3 级中 质隔热耐磨单层祄里, C3 级 $815^{\circ} \mathrm{C}$ 体积密度 $1400 \mathrm{~kg} / \mathrm{m}^{3}$, C2 级 $815^{\circ} \mathrm{C}$ 体积密度 $1600 \mathrm{~kg} / \mathrm{m}^{3}$, 较比双层隔热耐磨祄里体积 密大, 针固钉的焊接形式选用 UOP 文件要求, $\Omega$ 型针固钉直段背向开口方向一侧全长度焊接, 应对再生器内部氧化、 脱碳、渗碳、渗氮、氢蚀及硫化氢等腐蚀, 这种焊接形式使针固件与设备内壁的连接更可靠, 但焊接量增大了, 焊材 增加一倍, 焊接周期扩大一倍, 国标形式每人一天能焊接 600 个, 现在只能焊接 300 个, 在提出材料计划、编排施工 计划时均不能忽略。

4.1 .2 再生器内件龟甲网安装、焊接

再生器内件采用单层龟甲网高耐磨祄里, 龟甲网直接与设备壁板焊接, 技术角度分析龟甲网与内壁焊接质量相对 容易控制, 龟甲网在内壁上的拼接缝连接更加可靠。龟甲网安装前需要先对设备进行喷砂除锈, 然后采用单片逐张焊 接的方法进行安装。龟甲网预先放样下料, 下料前对龟甲网质量进行检查, 不符合要求的不得使用, 采用断丝剪进行下 料, 严禁火焰切割。

龟甲网下料时应留出搭接余量, 两龟甲网的接合处, 必须将每一个端头和龟甲网孔全部相互满焊连接牢固。龟甲 网滚制方向与钢带长度方向一致, 预制完的龟甲网应对尺寸复测, 其结扣处有少量脱扣或松动时, 沿深度方向进行满 焊加固。

龟甲就位后, 采用手工电弧焊点焊固定, 固定时应注意接头位置, 相邻两张龟甲网纵向拼缝要错开 $300 \mathrm{~mm}$ 以上, 龟甲网安装后结扣的间隙及错边不得大于 $0.5 \mathrm{~mm}$, 龟甲网直接焊在器壁上的, 需要与器壁贴紧, 间隙不得大于 $1 \mathrm{~mm} 。$

\section{2 基层处理技术要求}

4.2.1 设备金属表面处理应采用喷砂除锈，局部也可采用动力工具除锈，并符合下列规定：

(1)喷砂除锈磨料应采用金刚砂、石英砂、硅质河沙。

(2)磨料的颗粒直径宜为 $3 \sim 5 \mathrm{~mm}$ 。

(3)除锈前应对设备内容易堵塞或损坏的附件采取保护措施。

(4)采用喷砂除锈时，针固件宜在除锈前焊接，局部采用动力除锈时，针固件应在除锈后焊接。

(5)除锈时不应造成金属表面的损伤。

4.2.2 衬里施工前进行彻底的喷砂除锈, 除锈等级应达到国家标准《涂装前钢材表面锈蚀等级和除锈等级》GBT/8923 规定的 Sa1 级要求 (在不放大的情况下观察, 表面无可见的油、脂和污物, 无附着不牢的氧化皮、铁锈、涂层和外来 杂质); 局部喷砂有困难时, 可以采用手工电动达到除锈 St2 级要求, 除锈后的金属表面应及时清理干净, 并尽快祄里, 否则采取防雨、防潮措施，以防止返锈。

4.2.3 由于喷砂作业很难避免尘土飞扬, 喷砂除锈的时间宜在晚上进行。完成喷砂后, 应及时将设备清理干净, 龟 甲网结构孔距小很难清扫, 且龟甲网角部很容易残留泥土结块, 现场可以用钢雉配合吸尘器清理。祄里基层处理完成, 
建筑工程与管理・2019 第1卷 第2期

应组织相关人员再次验收，并填写《隐蔽工程检查记录》。
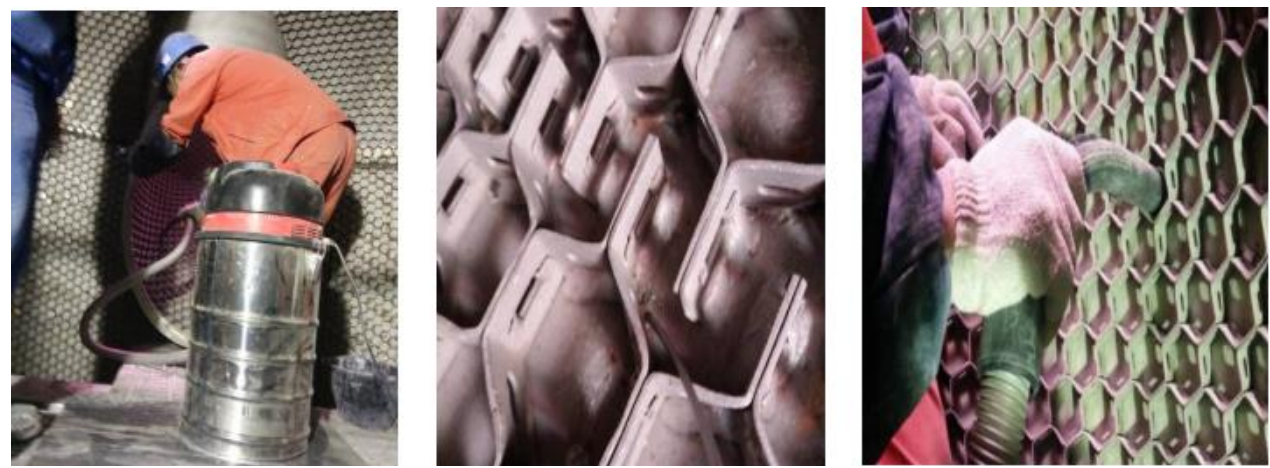

图 3 喷砂作业图

\section{3 再生器封头、壳体的单层隔热耐磨衬里施工}

\section{3.1 现场布置与准备}

再生器封头祄里采用 C3 单层隔热耐磨钢纤维祄里料，现场手工捣打施工，施工前将封头仰口布置。

(1)在封头的两侧人孔处分别就近搭设拌制平台, 拌制平台尺寸应满足需要, 平台底部满铺钢平台, 平台平整离地 $200 \mathrm{~mm}$ 。设备人口处搭设双跳板平台用于传料, 平台高度适宜。每侧人孔处安放台强制式搅拌机, 一个电子秤, 2 桶施 工用水, 祄里料大约 2 箱并根据施工进度及时补料。

(2)放置在现场拌制平台的祄里料顶部有防雨篷, 底部应支垫。即将拌制的祄里料, 当临时放在摚拌机附近时远离 水桶, 避免加水或补充水量时溅湿祄里料而影响祄里质量。电子秤安放平稳。

(3)基层喷砂后，用吸尘器结合毛刷清理设备内壁。

4. 3.2 祄里拌制

(1)祄里配比: 祄里应严格安装厂家事先包装的配比加料, 一袋集料配一袋结合剂, 加水量等按照产品说明书添加。 在拌制区域的显眼位置悬挂配合比标识牌。

(2)祄里搅拌: 根据现场搅拌材料情况, 搅拌设备全部由厂家指导采购, 其转速和材质要达到技术要求。材料按配 合比倒入搅拌机, 加料时加料员应注意材料包装完好情况, 材料的批号和日期, 结合剂每袋检查无结块等异常情况才 能倒入搅拌机中，包装破损的或有异常的材料不得使用，单独标注并及时反馈。

(3)祄里摚拌伙长在祄里出盘前判断祄里料的和易性, 定期检测祄里的出盘温度, 并填写《祄里摚拌记录》。
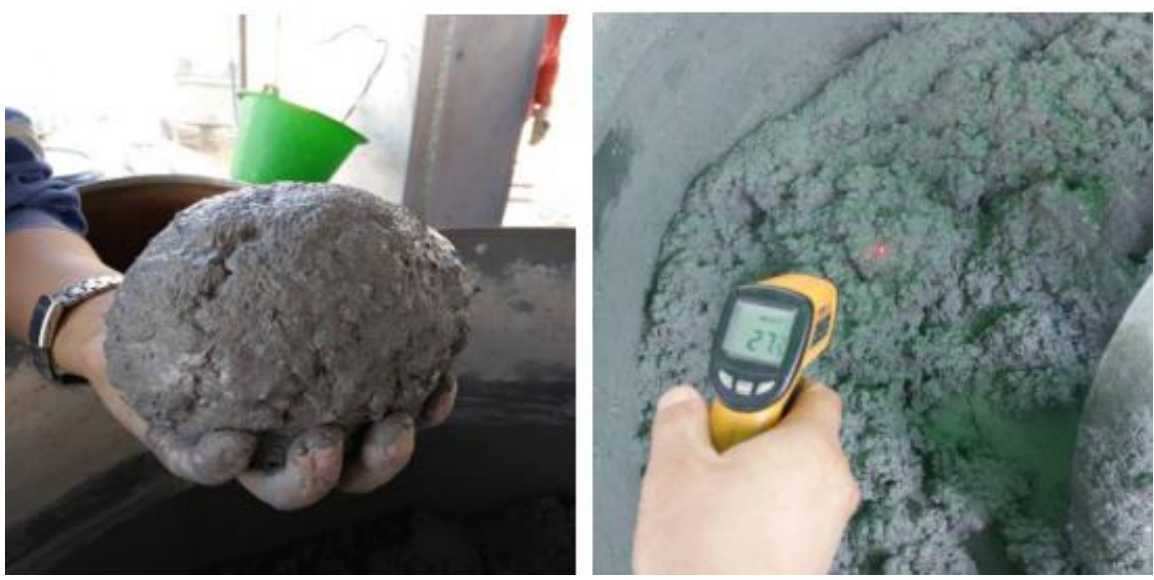

图 4 祄里拌制图

\section{3.3 祄里出盘}

用时应出一次出完，装入桶内，不宜过满防止洒落消耗，装桶后及时运至作业平台。

祄里出盘后及时清理搅拌桶，防止已经初凝的旧料混入新料影响质量，作业平台定时清理。 
祄里运送人员及时反馈祄里作业平台的祄里需用量, 按需用拌制祄里, 一次搅拌在 30 分钟内用完, 剩余的材料或 超过初凝时间开始发硬的材料弃之不用。所有的祄里材料不得二次加水搅拌使用。

4. 3.4 祄里布料与捣打

(1) 祄里运送到作业平台后, 倒出的祄里料重新揉成团, 使成球的祄里相对密实。

(2)祄里布料时, 将团好的祄里料用力摔打到器壁上, 每次的布料高度不大于 $300 \mathrm{~mm}$, 厚度方向一次成型。布料过程 中遇到针固钉胶帽脱落时及时补按。

祄里料在初凝前捣实后, 按设计图纸的外形尺寸进行整形, 高度方向多层同时施工时, 两层祄里交界处应捣打平 整不得有错台, 每隔 $400 \mathrm{~mm}$ 用探针测试一下厚度, 以防厚度偏差过大。

祄里找平、压实时后及时切除插管上外露纤维纸, 祄里表面拉毛, 严禁表面刷水、水泥浆或撒干粉。

\section{5 结束语}

哈萨克斯坦 PKOP 奇姆肯特炼油现代化改造工程, 以二 200 万吨/年重油催化裂化装置最核心, 其中反再系统的祄 里为特殊工序, 由于质量特征不能容易地通过后续的质量检验加以验证, 所以必须对祄里施工的全过程进行严密监控, 通过过程质量的控制以保证整个运行过程的祄里施工质量, 特别是随着装置运行周期化、原材料重质化及催化剂的硬 质化等因素使得操作工况越来越苛刻, 更应保证反应再生系统设备祄里质量, 在此我单位克服运输时间长、可依托资 源差、现场施工跨度周期大等原因, 科学组织、精心筹划、严密控制、精细检查, 较好地完成的该工程的祄里施工, 本文通过再生器的祄里施工过程进行了详细论述, 以反应整个反再系统祄里施工的过程, 可为类似工程提供借鉴。

\section{[参考文献]}

[1]王治国, 李达. 不负使命履行诺言- - PKOP 炼油厂现代化改造项目一期工程建设纪实 [J]. 石油知 识, 2017 (05): 16-18.

[2]袁莲, 王治国, 张欣。中国石油海外最大炼油厂项目 “解密”- - 工程建设公司奇姆肯特炼油厂现代化改造工程记 [J]. 石油知识, 2017 (01) : 16-17.

作者简介: 张勇 (1977-), 毕业至今一直在石油工程建设中从事工程管理工作, 中级工程师。 